\title{
Surface photochemistry of the herbicide napropamide. The role of the media and environmental factors in directing the fates of intermediates $\dagger$
}

\author{
Received 31st August 2007, Accepted 15th October 2007 \\ First published as an Advance Article on the web 31st October 2007 \\ DOI: $10.1039 / \mathrm{b} 713369 \mathrm{c}$
}

José P. Da Silva, ${ }^{* a}$ Edgar V. Bastos, ${ }^{a}{ }^{\text {Luis F. V. Ferreira }}{ }^{b}$ and Richard G. Weiss ${ }^{c}$

The photochemical behaviour of the herbicide napropamide is studied on cellulose and silica surfaces, using steady-state and laser-flash diffuse reflectance techniques. The results are used to probe how the reaction sites of the host matrices influence the photo-reactive pathways. Napropamide undergoes reaction when irradiated with UV (lamps) or visible (sunlight) radiation on both solid supports. The nature of the intermediates and final products depend strongly on the presence or absence of molecular oxygen. The triplet state of napropamide adsorbed on cellulose is detected by both time-resolved luminescence and transient absorption spectroscopies. The triplet sate was not observed on silica, but transients which include the participation of molecular oxygen are detected during flash photolysis studies. The keto intermediates of the photo-Claisen rearrangement products are observed on both solids. Substituted 1-naphthols from photo-Claisen reactions and 1-naphthol are among the main reaction products. 1,4-Naphthoquinone is a major photoproduct in the presence of molecular oxygen and is expected to be prevalent when napropamide undergoes photodegradation in the environment (i.e., after being applied to plants and fields).

\section{Introduction}

Photochemical transformations are a principal means by which organic molecules such as herbicides and pesticides are removed from the environment. ${ }^{1}$ There are, however, literally hundreds of chemically different organic xenobiotics and they are dispersed on many diverse types of natural surfaces. Thus, it is difficult to determine how a specific molecule is degraded photochemically in nature because there may be several distinct routes which depend on specific environmental conditions. Fortunately, examination of the photochemistry of one specific chromophoric group common to several herbicides and pesticides inside or on the surfaces of representative media which approximate those in natural environments can serve as a model for the family. Napropamide [2-( $\alpha$-naphthoxy) $-N, N$-diethylpropionamide] (Fig. 1) is such a herbicide and naphthyl is such a chromophore.

Napropamide has been reported to undergo photo-Claisen reactions in aqueous media., ${ }^{2,3}$ Photo-Claisen reactions of 1naphthyl alkyl ethers are known to proceed mainly from their excited singlet states via homolytic scission of the $\mathrm{C}-\mathrm{O}$ bond between the naphthoxy and alkyl moieties (Fig. 1). ${ }^{4}$ The 1naphthoxy and alkyl geminate radical pairs thus formed undergo cage recombination, leading to the Claisen products, after tautomerization of the initial keto intermediates $\left(\mathbf{I}_{1}\right.$ and $\mathbf{I}_{2}$, Fig. 1). The fraction of radical pairs that undergoes cage-escape usually

${ }^{a} F C T$, Universidade do Algarve, Campus de Gambelas, 8005-139, Faro, Portugal. E-mail: jpsilva@ualg.pt; Fax: +351 289800 066; Tel: +351 289 800900 , ext. 7644

${ }^{b}$ Centro de Química-Física Molecular, Instituto Superior Técnico, 1049-001, Lisboa, Portugal

'Department of Chemistry, Georgetown University, Washington, DC, 200571227, USA

$\dagger$ Electronic supplementary information (ESI) available: Experimental details and product spectra. See DOI: $10.1039 /$ b713369c

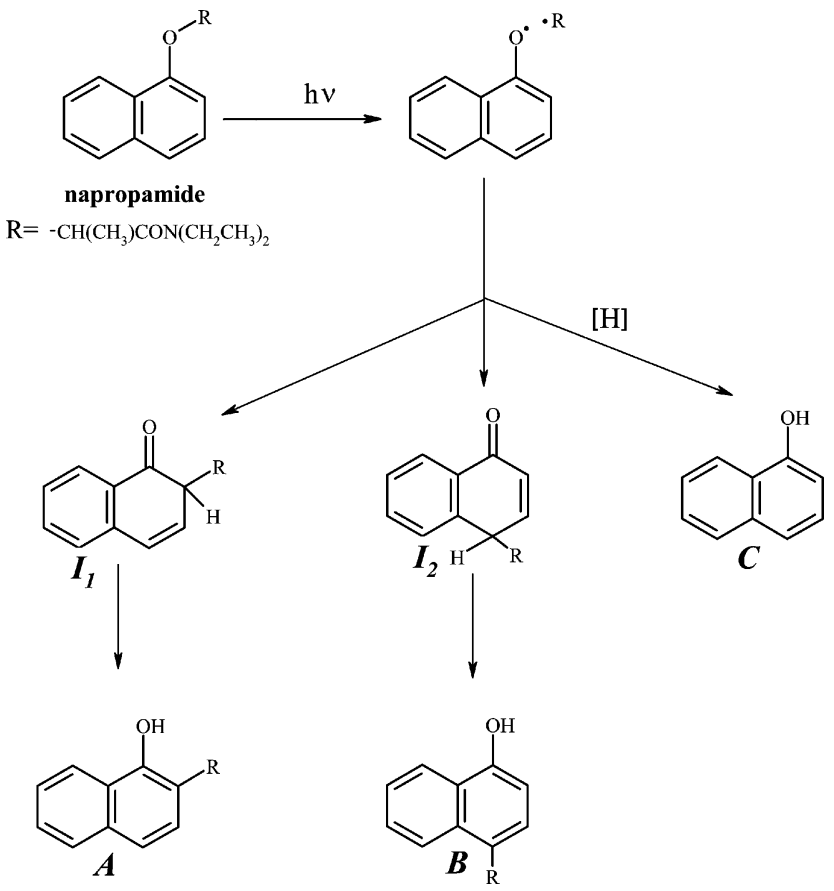

Fig. 1 Simplified scheme for photo-Claisen reactions of napropamide.

results in the formation of 1-naphthol if the medium contains abstractable $\mathrm{H}$-atoms. ${ }^{5}$ Although $\mathrm{H}$-atom abstractions are slightly endoergonic from most of the $\mathrm{C}-\mathrm{H}$ bonds in a polymer such as cellulose, they can occur when the naphthoxy radicals live for a long time and because there exist many 'defect' sites in this complex polymer that afford more attractive $\mathrm{C}-\mathrm{H}$ bonds as $\mathrm{H}$-atom donors. Additionally, when molecules of napropamide are either aggregated or in high local concentration, bimolecular formation of naphthol, involving abstraction of an $\mathrm{H}$-atom from 
one molecule by a naphthoxy fragment of another, can become important. Regardless, the fate of the radical pairs is sensitive to the nature of their immediate environment, and that sensitivity can be monitored by the distributions of photoproducts obtained. ${ }^{4}$ Thus, the excited states and other intermediates involved in the photoClaisen rearrangements (and related photo-Fries rearrangements of aromatic esters) are very useful in assessing the influences of different reaction environments on molecular motions over short distances. $^{4-11}$ )

The specific photo-Claisen products from napropamide are $N, N$-diethyl-2-(1-hydroxynaphthalene-2-yl)propionamide (A) and $N, N$-diethyl-2-(4-hydroxynaphthalene-1-yl)propionamide (B), as well as the cage-escape product, 1-naphthol $(\mathbf{C})$. Although the photoreactions of napropamide have been examined on soil surfaces, ${ }^{12,13}$ we are unaware of any spectroscopic or photoproduct distribution studies employing it at solid-gas interfaces.

Here, we examine both the nature of the transients and the distributions of the photoproducts from napropamide adsorbed on the solid surface of silica and at two locations on cellulose. This study provides mechanistic information about the interactions between napropamide and its intermediates and these solid surfaces, and insights into how napropamide and other systemic herbicides and pesticides with similar structures ${ }^{14}$ are degraded by solar radiation when they are applied to soils and plants.

\section{Experimental}

\subsection{Materials}

Napropamide (Chem Service, 99.0\% (GC)), 1,4-naphthoquinone (Fluka, $\geq 99 \%$ (UV), 1-naphthol (Riedel-de Haën, 99.8\% (GC)), microcrystalline cellulose powder DSO (Fluka, $\leq 5 \%$ loss on drying at $100{ }^{\circ} \mathrm{C}$ for $24 \mathrm{~h}$; additive free according to supplier), silica gel $60(60 \AA$ pore size, Fluka, $6 \%$ mass loss after $5 \mathrm{~h}$ at $130{ }^{\circ} \mathrm{C}$ ), methanol and acetonitrile (Merck Lichrosolv), and hexane (Merck, p.a.) were used without further treatment. Water was deionized and distilled.

\subsection{Sample preparations}

The samples $\left(2.5,25,50,100\right.$ and $250 \mu \mathrm{mol}$ napropamide $\mathrm{g}^{-1}$ support) were prepared using a solvent evaporation method..$^{15}$ Adsorption of napropamide onto unactivated and activated $\left(130^{\circ} \mathrm{C}, 5 \mathrm{~h}\right)$ silica was achieved by adding the support to a hexane solution of napropamide and allowing them to equilibrate for $12 \mathrm{~h}$ while being stirred in a closed vessel. The mixtures were then stirred continuously in open vessels until the solvent had evaporated. Samples on cellulose were prepared in the same way, but using methanol as the solvent. The final concentration of napropamide was determined by extracting a known weight of sample with a known volume of methanol, followed by centrifugation, and comparing their HPLC chromatograms (relative peak areas) with those of standard solutions. This extraction procedure recovered $100 \%$ (within the experimental error) of the adsorbed napropamide based on the weights of the mixed species.

Washed cellulose samples (to remove napropamide at external surfaces) were also prepared and analysed. Typically, $50 \mathrm{mg}$ of sample was mixed with $5 \mathrm{~mL}$ of hexane and allowed to equilibrate during 1-2 min. The mixture was then filtered and the solvent was evaporated. This process resulted in the removal of $10-15 \%$ of the napropamide at $50 \mu \mathrm{mol} \mathrm{g}^{-1}$ initial loading.

\subsection{Methods}

Irradiations, kinetics, and product analyses. Photolyses were conducted in an apparatus described previously ${ }^{16,17}$ Radiation, principally at $254 \mathrm{~nm}$, was from the unfiltered output of a $16 \mathrm{~W}$ low-pressure mercury lamp (Applied Photophysics), placed $1 \mathrm{~cm}$ above the sample surface. The samples were also irradiated with a medium pressure xenon lamp, with and without a Pyrex ${ }^{\mathrm{TM}}$ filter. In some cases (mentioned specifically in the text), irradiations were also performed in sunlight under clear skies at Algarve, Portugal $\left(37^{\circ} \mathrm{N}\right.$ latitude and $8^{\circ} \mathrm{W}$ longitude, $\left.20-28^{\circ} \mathrm{C}\right)$ in April/May of 2006. The sunlight radiation intensities as a function of wavelength, latitude, and time of year are tabulated in reference. ${ }^{1}$ At $300 \mathrm{~nm}$ and $40^{\circ} \mathrm{N}$ in Spring, the value is $1.06 \times 10^{-7}$ einstein $\mathrm{cm}^{-2} \mathrm{day}^{-1}$. For experiments to obtain information about the photo-degradation kinetics and product distributions, solid powder $(30-50 \mathrm{mg})$ was spread on glass microscope slides and covered with quartz slides. The edges of the slide sandwiches were sealed with Parafilm ${ }^{\mathrm{TM}}$ to prevent loss of materials. In some experiments, argon or oxygen gas was flowed through samples in quartz cells for $c a .30 \mathrm{~min}$ and the cells were sealed prior to irradiation.

After irradiation, a weighed amount (10-15 mg) of sample irradiated within a $1 \mathrm{~cm}^{2}$ area was placed in $1 \mathrm{~mL}$ of methanol, the mixture was shaken vigorously, and the solid was allowed to settle. The liquid was then analyzed by HPLC.

The amounts of napropamide and 1,4-naphthoquinone were determined by comparing the peak areas from injections of a known amount of the methanol extract with those from a calibration curve obtained with standard solutions. The concentrations of the other photoproducts detected at $300 \mathrm{~nm}$ were estimated by assuming that their extinction coefficients are that of 1naphthol at this wavelength. The reported uncertainties are the standard deviations calculated for more than five measurements. The quantifications were performed only on samples irradiated in air equilibrated conditions. Analyses of silica and cellulose samples kept in the dark for more than three months showed no sign of napropamide degradation. Extracts of non-irradiated and irradiated samples were also analyzed by GC-MS.

Ground state absorbance spectra. The ground state absorption spectra on silica were obtained with a UV-Vis spectrophotometer equipped with a diffuse reflectance attachment. The absorption spectra on cellulose were obtained using the laser setup described in the ESI. $\uparrow$ The method is explained in detail elsewhere ${ }^{18}$ and allows for correction of signals from luminescence

Diffuse-reflectance laser flash photolysis (DRLFP) and laserinduced luminescence (LIL). Laser flash photolysis experiments were carried out with the third harmonic of a Nd:YAG laser in the diffuse reflectance mode. The excitation source for the LIL experiments was an $\mathrm{N}_{2}$ laser. The detection was performed using an ICCD detector.

Details about the equipment used for ground state absorbance and calculation of the ground state absorbance spectra, the HPLC and GC-MS instruments and the conditions of their operation, and the laser apparatus are described in the ESI.† 


\section{Results and discussion}

\subsection{UV-vis absorption spectra}

Napropamide and its aromatic photoproducts are able to undergo direct phototransformation in nature because their absorption spectra overlap partially the solar radiation striking the Earth's surface near sea level $\left(>290 \mathrm{~nm}^{1}\right)$. The absorption spectra of napropamide on both silica and cellulose are similar to those obtained in solution (Fig. 2). The band between 250 and $330 \mathrm{~nm}$ corresponds to a $\pi \rightarrow \pi^{*}$ transition of the naphthoxy group. Photoreaction increases the absorbance between $250 \mathrm{~nm}$ and $c a$. $500 \mathrm{~nm}$, indicating the formation of new products (Fig. 2, spectrum 3 ), some of which have higher molar extinction coefficients than the herbicide itself.

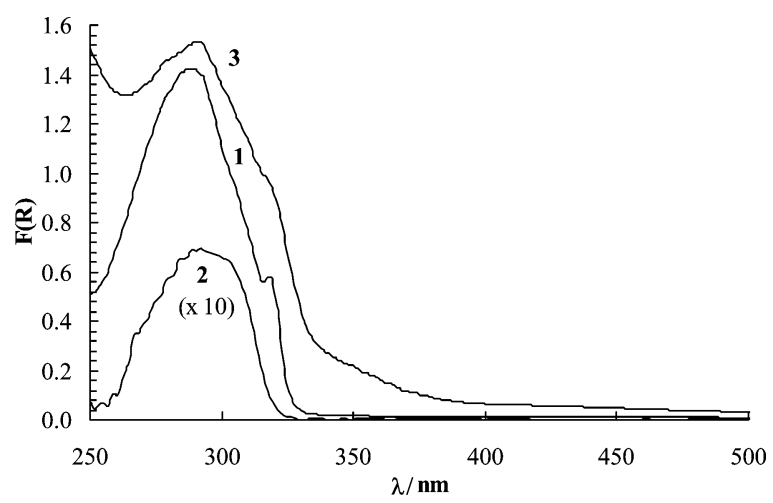

Fig. 2 Remission function spectra at room temperature of non-irradiated napropamide on silica $\left(1,50 \mu \mathrm{mol} \mathrm{g}^{-1}\right)$ and on cellulose $\left(2,2.5 \mu \mathrm{mol} \mathrm{g} \mathrm{g}^{-1}\right)$ and irradiated in air on silica $\left(3,50 \mu \mathrm{mol} \mathrm{g}^{-1}\right)$ for $1 \mathrm{~min}$ at $254 \mathrm{~nm}, 1 \mathrm{~cm}$ from the lamp surface.

\subsection{Time-resolved luminescence and transient absorption studies}

Time-resolved luminescence spectra of napropamide on cellulose in air consisted of a broad band centred at about $520 \mathrm{~nm}$ that decays in the millisecond time range (Fig. 3). The emission spectra are similar to those reported by Pulgarín et al. ${ }^{19}$ and are assigned to napropamide phosphorescence. Room temperature

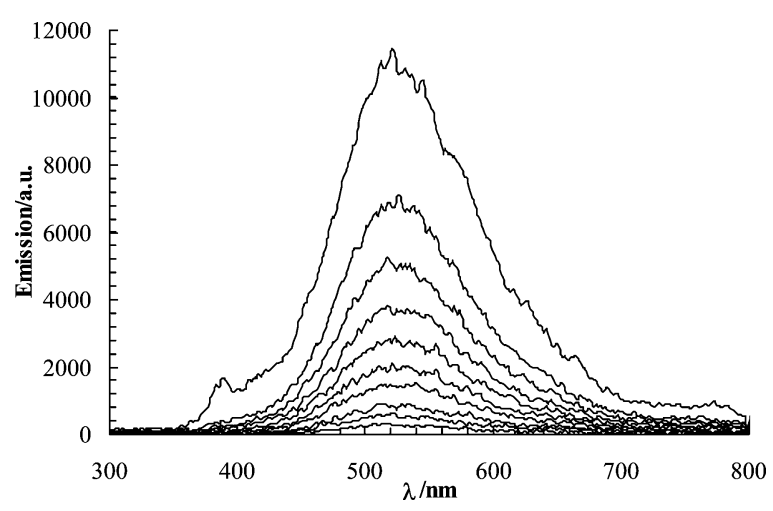

Fig. 3 Emission spectra of napropamide on cellulose $\left(50 \mu \mathrm{mol} \mathrm{g}^{-1}\right)$ in air after pulsed laser excitation $\left(337 \mathrm{~nm}, \sim 1 \mathrm{~mJ}\right.$ pulse ${ }^{-1}, 600 \mathrm{ps}$ pulse width, $500 \mathrm{~ns}$ gate width). Spectra were recorded at delays of 1.0, 3.0, 5.0, 7.0, $9.0,11.0,13.0,15.0,17.0$, and $19.0 \mathrm{~ms}$ (from top to bottom) after the laser pulse. phosphorescence (RTP) has been observed for several molecules adsorbed on cellulose, and it is a well-documented phenomenon, especially when the delivery agent for adsorption is a hydroxylic solvent that swells the polymer and allows the guest molecules to be placed well below the polymer surfaces. ${ }^{20}$ The probe molecules become entrapped between polymer chains, in a rigid environment that is somewhat protected from molecular oxygen. The slowed diffusion of oxygen to the sites where the molecules in their triplet states reside allows phosphorescence to be observed.

The triplet state of napropamide adsorbed on cellulose was also detected by transient absorption spectroscopy. The triplet-triplet absorption of similar naphthoxy derivatives has been reported to have a maximum near $430 \mathrm{~nm} \cdot{ }^{20-23}$ Naphthyl acetates show a somewhat lower absorption maximum at $417 \mathrm{~nm} .{ }^{5}$ The transient absorption spectrum of napropamide on cellulose obtained at pulse end ( $20 \mathrm{~ns}$ ) shows a sharp absorption band at $340 \mathrm{~nm}$ and the expected triplet-triplet absorption of napropamide centered around $425 \mathrm{~nm}$ (Fig. 4a). After $20 \mathrm{~ms}$, the absorbance at $340 \mathrm{~nm}$ decreased while the one at $425 \mathrm{~nm}$ nearly vanished.

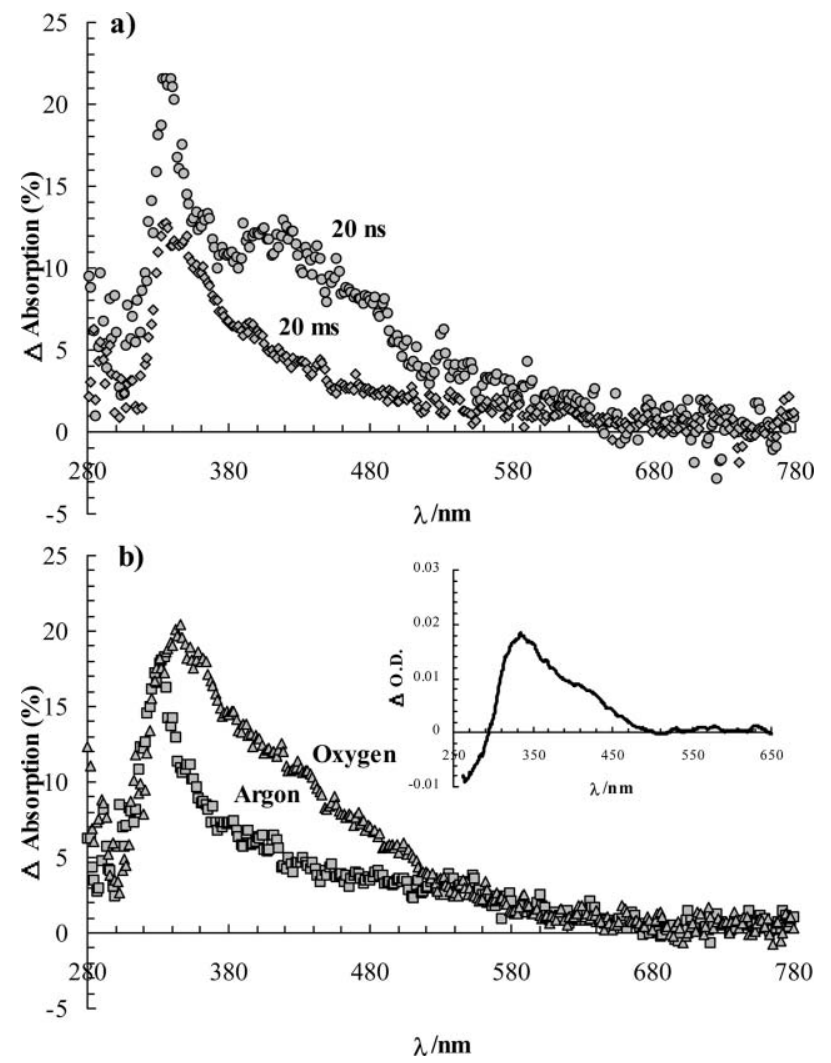

Fig. 4 Transient absorption of napropamide (a) on cellulose $\left(50 \mu \mathrm{mol} \mathrm{g}{ }^{-1}\right)$ in air-equilibrated conditions at $\sim 20 \mathrm{~ns}$ and $20 \mathrm{~ms}$ after a laser pulse, and (b) on silica $\left(50 \mu \mathrm{mol} \mathrm{g}{ }^{-1}\right)$ under argon and oxygen atmospheres at $\sim 20 \mathrm{~ns}$ after the laser pulse (266 nm excitation, $6 \mathrm{~ns}$ FWHM, $30 \mathrm{~mJ}$ pulse $^{-1}$, $500 \mathrm{~ns}$ gate width). The inset shows the transient absorption obtained for napropamide in and air-equilibrated aqueous solution at pulse end (O.D. $\sim 0.4,266 \mathrm{~nm}, 30 \mathrm{~mJ}$ pulse ${ }^{-1}, 500 \mathrm{~ns}$ gate width).

By contrast, the characteristic triplet-triplet absorbance of the naphthoxy moiety was not detected on silica, even when the pulsed excitation was performed on a sample under argon atmosphere (Fig. 4b). Failure to observe the napropamide triplet state on silica (even under an argon atmosphere) indicates that factors besides 
the presence or absence of oxygen determine the stability of the triplet states and the efficiency of their emission.

The absorption maximum at $390 \mathrm{~nm}$ and a low intensity absorption band between 400 and $650 \mathrm{~nm}$, expected for a 1naphthoxy radical, ${ }^{24,25}$ were not apparent in transient absorption spectra from samples with cellulose or silica supports. The lifetime of the geminal radical pairs from lysis of napropamide may be too short to be detected after the $c a$. 20 ns of our laser pulses-1naphthoxy/acetyl radical pairs combine in acetonitrile at room temperature in less than $1 \mathrm{~ns}^{26}$ - or to the presence of other transients absorbing in the same spectral region.

For comparison purposes, the transient absorption of napropamide was also studied in aqueous solution (inset of Fig. 4b). As mentioned, formation of the photo-Claisen products involves recombination of the radical pair, leading initially to intermediates $\mathbf{I}_{\mathbf{1}}$ and $\mathbf{I}_{\mathbf{2}}$ (Fig. 1). The tautomerization of these keto intermediates to the isolated 'enolic' forms, $\mathbf{A}$ and $\mathbf{B}$, in solution occurs over periods of microseconds to seconds, depending upon the availability of acid or base catalysts, ${ }^{11}$ The keto intermediates exhibit an absorption band near $320 \mathrm{~nm} .{ }^{26}$ On this basis, we assign the spectral feature with a maximum at $330 \mathrm{~nm}$ to compounds $\mathbf{I}_{\mathbf{1}}$ and $\mathbf{I}_{2}$. The negative absorption change at shorter wavelengths is due to depletion of napropamide. The absorptions between 320 and $360 \mathrm{~nm}$ observed on silica and cellulose must be due to the keto intermediates as well as photoproducts $\mathbf{A}$ and $\mathbf{B}$, especially at longer times (See Figure $\mathrm{S}-1 \dagger$ ). On the silica surface, the absorbance increases between 330 and $530 \mathrm{~nm}$ under air and oxygen atmospheres (Fig. 4b). It is ascribed to transients from reaction of naphthoxy radicals and molecular oxygen (vide infra).

\subsection{Photoconversion and photoproducts}

The direct conversion of napropamide to photoproducts occurs upon irradiation at $254 \mathrm{~nm}$ and also in sunlight (Table 1). The relative phototransformation rates are somewhat higher on silica than on cellulose, and they decrease slightly with increasing surface coverage in the range from 2.5 to $250 \mu \mathrm{mol} \mathrm{g}{ }^{-1}$. The lower rates on cellulose may be due to absorption of some radiation by the support itself ${ }^{15,20}$ and to the availability of additional reaction pathways on silica involving molecular oxygen. However, similar photodegradation rates were found on unactivated (i.e., as received and, therefore, hydrated) and activated (i.e., preheated at $130{ }^{\circ} \mathrm{C}$ for $5 \mathrm{~h}$ to remove water and some hydroxyl surface sites) silica.

The distributions of photoproducts from napropamide were first studied in aqueous solutions. The major products detected, $\mathbf{A}$, B, and naphthol (C) (Fig. 3), are consistent with previous reports ${ }^{2,3}$ and account for nearly $100 \%$ of the consumed napropamide after ca. $15 \%$ conversion. At higher conversions, the initial photoproducts undergo secondary reactions, leading to unidentified species, and the mass balance becomes poorer.

At very low photoconversions $(<5 \%)$ on cellulose and silica, the photoproducts, A, B, naphthol (C) and naphthoquinone (D) (Fig. 5), account for $60-75 \%$ of the consumed napropamide after irradiation at $254 \mathrm{~nm}$ or in sunlight. At higher conversions, the mass balance becomes poorer, indicating (as in aqueous media) that the initial photoproducts undergo efficient secondary reactions. The presence of photoproducts covalently bonded to the cellulose matrix especially, ${ }^{16,17,27}$ may contribute to the lack of a good mass balance. However, the absorption spectra of the extracted samples after irradiation are $<5 \%$ as intense at all wavelengths than before extraction.

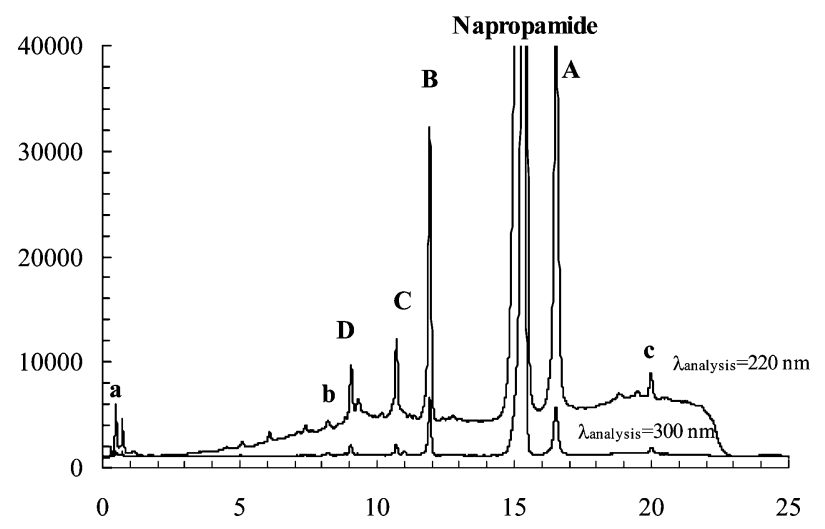

Fig. 5 HPLC chromatograms at 220 and $300 \mathrm{~nm}$ as the detector wavelengths of the extracted product mixture from an irradiated $(254 \mathrm{~nm})$ sample of napropamide on silica $\left(50 \mu \mathrm{mol} \mathrm{g}^{-1}\right)$. Several unidentified minor products are apparent. The conversion of napropamide was $\sim 15 \%$; peaks $\mathbf{a}, \mathbf{b}$, and $\mathbf{c}$ are unidentified products.

The keto intermediates in Fig. 1 are known to be photochemically labile. ${ }^{26}$ The slower is their tautomerism, the more likely they can absorb a photon and undergo a secondary photochemical reaction. In fact, $\alpha$-cleavage of the keto intermediates in the photo-Fries and photo-Claisen rearrangements to form dienic ketenes has been documented by flash photolysis studies. ${ }^{28}$ Thus, stabilization of the keto intermediates of napropamide on cellulose or silica may increase the fraction of reaction that does not yield eventually one of the classic photo-Claisen products (and account for the decreases in the mass balances with increasing conversion). HPLC analyses at $220 \mathrm{~nm}$ (Fig. 5) and other detection wavelengths of the extracts from napropamide irradiated on both solid supports indicate the formation of products containing only one aromatic

Table 1 Photodegradation of napropamide on silica and cellulose at $254 \mathrm{~nm}$ and in sunlight in air

\begin{tabular}{|c|c|c|c|c|c|c|c|c|}
\hline \multirow{3}{*}{$\begin{array}{l}\frac{\text { Initial concentration } / \mu \mathrm{mol} \mathrm{g}^{-1}}{\text { Radiation }} \\
\text { Irradiation time }\end{array}$} & \multicolumn{4}{|c|}{ Silica $^{a}$} & \multicolumn{4}{|c|}{ Cellulose $^{a, b}$} \\
\hline & \multicolumn{4}{|c|}{$48.9 \pm 2.2$} & \multicolumn{4}{|c|}{$48.4 \pm 2.5$} \\
\hline & $5 \min$ & $14 \mathrm{~h}$ & $0.5 \mathrm{~h}^{c}$ & 1 day & $5 \mathrm{~min}$ & $14 \mathrm{~h}$ & $0.5 \mathrm{~h}^{c}$ & 1 day \\
\hline Final concentration $/ \mu \mathrm{mol} \mathrm{g}{ }^{-1}$ & $40.5 \pm 2.3$ & $18.6 \pm 2.5$ & $35.2 \pm 1.8$ & $2.8 \pm 2.3$ & $43.3 \pm 2.5$ & $22.5 \pm 1.5$ & $37.3 \pm 2.2$ & $21.9 \pm 2.9$ \\
\hline
\end{tabular}


ring (i.e., absorbing at $220 \mathrm{~nm}$, but not at $>300 \mathrm{~nm}$; see Fig. $\mathrm{S}-2 \dagger$ ). This observation is consistent with there being secondary photoreactions of the initially formed (major) photoproducts.

On cellulose, the photoproduct distributions are similar at napropamide loadings between $2.5 \mu \mathrm{mol} \mathrm{g} \mathrm{g}^{-1}$ and $250 \mu \mathrm{mol} \mathrm{g}$. On silica, increased loadings result in higher relative yields of product c (see Fig. 5 and Fig. S-2†). A possible explanation for this observation is that formation of product $\mathbf{c}$ involves a bimolecular process. A photoproduct with a high retention volume, assigned to a dimer of product $\mathbf{A}^{2}$, was previously reported from irradiations of napropamide in aqueous solutions. In support of this contention, the photoproduct distributions are similar when irradiations are conducted on activated or unactivated silica.

Products $\mathbf{A}$ and $\mathbf{B}$ were identified by comparison with their reported spectra while the structure for $\mathbf{C}$ was deduced from comparison of its properties with those of an authentic sample. An oxidation product, 1,4-naphthoquinone (D), was observed after irradiations on silica in an air atmosphere. Its structure was established by comparison of its HPLC retention volume and MS spectrum with those of an authentic sample. Irradiations of cellulose samples in the presence of oxygen also lead to $\mathbf{D}$, but in lower relative yields. $\mathbf{D}$ is not detected after irradiations under an argon atmosphere on both solid surfaces. The presence of $\mathbf{D}$ also contributes to the aforementioned increased absorption of the irradiated samples observed in spectrum 3 of Fig. 2.

\subsection{Role of environmental factors in the reaction pathways}

The photochemical behaviour of napropamide on the solid surfaces is similar in some respects (and very different in others) to that reported in aqueous solutions. The formation of the Claisen products and 1-naphthol clearly indicate that the primary photoreaction step on the solid supports is homolytic cleavage of the napthoxy-alkyl $\mathrm{C}-\mathrm{O}$ bond of napropamide (Fig. 1). The photoproduct distributions shown in Table 2 indicate that the local motions of the transients within the sites afforded by cellulose do not differ significantly from those in aqueous solutions. A major difference, in the enhanced yields of 1-naphthol, was expected because cellulose is known to be a good $\mathrm{H}$-atom donor. ${ }^{5,15-18,20}$ The presence of some 1-naphthol upon irradiations of napropamide in water and on silica, two environments that lack easily abstractable $\mathrm{H}$-atom sources, and the significantly less than $100 \%$ mass balance at even low conversions on cellulose and silica suggest that other reaction pathways for the formation of this compound can occur both in aqueous solution and on the surfaces studied here. Another source of easily abstractable Hatoms is napropamide itself, as well as other radicals or transients (such as the keto intermediates). H-abstraction by 1-naphthoxy radicals from napropamide molecules and species derived from it on silica and cellulose may account for the less than 100\% mass balances for the products in Fig. 1 as reported in Table 1. However, we have not been able to detect the napropamide-like species which should be present if such processes are important. As found during photo-Claisen rearrangements of benzyl 1-naphthyl ether in another polymeric material, polyethylene films, ${ }^{4}$ the reaction sites afforded by cellulose appear to allow significant local motions by the napropamide radical pairs ${ }^{29}$; however, the high viscosity of the cellulose medium should retard processes that depend on bulk diffusion of large fragments from napropamide. Very different results have been observed when a matrix is rigid., ${ }^{9,10}$ In fact, the highest selectivity has been observed when the reaction sites possess cationic centers, suggesting that electrostatic interactions may be important, if available ${ }^{9}$

Similar behaviour was found on silica. The results suggest that a geminal radical pair on this solid support is not impeded from undergoing the rotational and short-distance translational motions that lead to formation of the keto tautomers of products $\mathbf{A}$ and $\mathbf{B}$, but as with cellulose, processes that depend on translational diffusion of the napropamide fragments over long distances should not be important. The higher local mobility expected at sites on silica is also consistent with the failure to detect the triplet state of napropamide molecules adsorbed on its surface even under an argon atmosphere; deactivation processes can compete efficiently with intersystem crossing by napropamide singlets and subsequent emission from the triplets. The formation of product $\mathbf{c}$ only on silica is also in agreement with the possibility of additional reaction channels for the transients on silica surfaces.

The formation of 1,4-naphthoquinone from irradiations on cellulose in air, although in lower yield than on silica, was somewhat unexpected based on the time-resolved luminescence spectra. However, this result is more reasonable if one considers that some napropamide molecules reside at or very near the surfaces of cellulose matrices and others are buried within the matrix. Napropamide molecules at sites near the surfaces are much more exposed to molecular oxygen, and their intermediates can lead to formation of 1,4-naphthoquinone. Based on Beer's law, electronic excitation (and, therefore, reaction) of napropamide molecules in these sites is more probable than in deeper, more constrained sites. Thus, the relative yield of 1,4-naphthoquinone on cellulose is expected to be (and is) highest at the lowest conversions: at $\sim 5 \%$ conversion, the A/D product ratio is one order of magnitude lower than at $25 \%$ conversion. To determine the role of nonentrapped napropamide molecules on the formation of product $\mathbf{D}$, we irradiated a cellulose sample whose surfaces had been washed

Table 2 Photoproduct distributions from napropamide under different conditions

\begin{tabular}{lccccccc}
\hline & & & \multicolumn{4}{c}{ Photoproduct distribution } \\
\cline { 5 - 7 } Medium & Irradiation & Conversion & $\mathbf{A}$ & $\mathbf{B}^{b, c}$ & $\mathbf{C}^{b, c}$ & $\mathbf{D}^{b, c}$ \\
& Water & $254 \mathrm{~nm}$ & $\sim 15 \%$ & 1.00 & $0.45 \pm 0.05$ & $0.10 \pm 0.05$ & - \\
Cellulose $^{a}$ & $254 \mathrm{~nm}$ & $<5 \%$ & 1.00 & $0.60 \pm 0.10$ & $0.40 \pm 0.10$ & $0.50 \pm 0.15$ \\
Cellulose $^{a}$ & $>290 \mathrm{~nm}$ & $<5 \%$ & 1.00 & $0.80 \pm 0.10$ & $0.35 \pm 0.10$ & $1.30 \pm 0.15$ \\
Silica & $254 \mathrm{~nm}$ & $<5 \%$ & 1.00 & $0.75 \pm 0.10$ & $0.10 \pm 0.05$ & $0.90 \pm 0.15$ \\
Silica & $>290 \mathrm{~nm}$ & $<5 \%$ & 1.00 & $0.60 \pm 0.10$ & $0.10 \pm 0.05$ & $1.95 \pm 0.20$
\end{tabular}

${ }^{a}$ Samples prepared using methanol. ${ }^{b}$ Relative to product A. ${ }^{c}$ One standard deviation. 
with hexane, a solvent which is unable to penetrate into the interior of bulk cellulose samples, ${ }^{20}$ but is able to remove surface-adsorbed napropamide molecules. As expected, only traces of product $\mathbf{D}$ were detected after irradiation of these samples.

Based upon these observations, the nature of the initial photoproducts from herbicides and pesticides is expected to be strongly dependent on their ability (as well as that of their intermediates) to diffuse on or to an air-solid surface (such as soil or a leaf). The diffusion of systemic herbicides and pesticides (structurally related to napropamide) to locations below plant surfaces should decrease the ability of molecular oxygen to come into contact with 1-naphthoxy radical intermediates before they follow a different reaction course and, thereby, decrease the yield of 1,4naphthoquinone.

The formation of 1,4-naphthoquinone was also observed when 1-methoxynaphthalene was irradiated on a silica surface; ${ }^{30}$ it was attributed to reaction of a ground-state molecule with singlet oxygen. Radicals, such as 1-naphthoxy, are also known to be very reactive towards molecular oxygen. ${ }^{31}$ It is, therefore, likely that the formation of 1,4-naphthoquinone results from reaction of molecular oxygen with the naphthoxy radical or with 1-naphthol itself. ${ }^{32}$ The transformation of the oxygen adducts to yield 1,4naphthoquinone can occur via several plausible routes. ${ }^{32}$

\section{Conclusions}

When irradiated by UV lamps or in sunlight on cellulose and silica supports, the herbicide napropamide undergoes interesting phototransformations. Homolytic cleavage of the 1-napthoxy-alkyl $\mathrm{C}-\mathrm{O}$ bond, leading to formation of photo-Claisen products and 1naphthol, is a major reaction pathway. In the presence of molecular oxygen, 1,4-naphthoquinone becomes a major product. Silica and cellulose restrict longer translational motions of napropamide and its fragments but allow the photochemically-generated radical pairs to move in a relatively unencumbered fashion within a reaction site; the rotational and diffusional motions within a reaction site are limited to a few $\AA$. The constrained (sub-bulk surface) reaction sites supplied by cellulose upon entrapment of napropamide retard contact between molecular oxygen and either the excited states of napropamide or its radical intermediates and, thus, the formation of 1,4-naphthoquinone.

These results provide valuable insights into how napropamide and other $\alpha$-naphtoxy herbicides and pesticides are transformed by sunlight after their deposition on natural surfaces. Based upon our observations, the diffusion of systemic herbicides and pesticides into the interior regions of plants after their deposition on surfaces lowers the ability of molecular oxygen to come into contact with 1-naphthoxy radical intermediates and, therefore, should decrease the amount of the initial material which is converted to 1,4-naphthoquinone. To confirm this hypothesis, other model surfaces need to be explored. Thus, we intend to investigate the photochemical behaviour of napropamide and its intermediates on $c a$. surfaces with cationic centers, ${ }^{9}$ since they are more similar than silica to the environments found in soil.

\section{Acknowledgements}

J. P. S. thanks FCT for a Post-Doctoral fellowship SFRH/BPD/15589/2001 and R. G. W. thanks the U.S. National Science Foundation for financial support.

\section{References}

1 A. Leifer, The Kinetics of Environmental Aquatic Photochemistry, Theory and Practice ACS Professional Reference Book, Maple Press Company, York, PA, 1988.

2 L. L. Chang, B. Y. Giang, K.-S. Lee and C. K. Tseng, Aqueous photolysis of napropamide, J. Agric. Food Chem., 1991, 39, 617-621.

3 J. P. Aguer, P. Boule, F. Bonnemoy and J. M. Chezal, Phototransformation of napropamide [N,N-diethyl-2-(1naphthyloxy)propionamide] in aqueous solution: influence of the toxicity of solutions, Pestic. Sci., 1998, 54, 253-257.

4 W. Q. Gu, M. Warrier, B. Schoon, V. Ramamurthy and R. G. Weiss, Understanding the influence of active (Zeolite) and passive (polyethylene) reaction cages on photo-Claisen rearrangements of aryl benzyl ethers, Langmuir, 2000, 16, 6977-6981.

5 W. Gu, S. Bi and R. G. Weiss, Photo-Fries rearrangements of 1naphthyl esters in the glassy and melted states of poly(vinyl acetate). Comparisons with reactions in less polar polymers and low-viscosity solvents, Photochem. Photobiol. Sci., 2002, 1, 52-59.

6 M. S. Syamala and V. Ramamurthy, Modification of photochemical reactivity by cyclodextrin complexation-selectivity in photo-Claisen rearrangement, Tetrahedron, 1988, 44, 7223-7233.

7 K. Pitchumani, M. Warrier and V. Ramamurthy, Remarkable product selectivity during photo-fries and photo-claisen rearrangements within zeolites, J. Am. Chem. Soc., 1996, 118, 9428-9429.

8 I. F. Molokov, Y. P. Tsentalovich, A. V. Yurkovskaya and R. Z. Sagdeev, Investigation of the photo-Fries rearrangement reactions of 1- and 2-naphthyl acetates, J. Photochem. Photobiol., A, 1997, 110, 159165.

9 W. Q. Gu, M. Warrier, V. Ramamurthy and R. G. Weiss, PhotoFries reactions of 1-naphthyl esters in cation-exchanged zeolite $\mathrm{Y}$ and polyethylene media, J. Am. Chem. Soc., 1999, 121, 9467-9468.

10 S. Koodanjeri, A. R. Pradhan, L. S. Kaanumalle and V. Ramamurthy, Cyclodextrin-mediated regioselective photo-Fries reaction of 1-naphthyl phenyl acylates, Tetrahedron Lett., 2003, 44, 3207-3210.

11 J. G. Xu and R. G. Weiss, Combinations of chiral and prochiral singlet radical pairs in reaction cavities of polyethylene films. Control and analysis of radical tumbling and translation, Photochem. Photobiol. Sci., 2005, 4, 348-358.

12 S. G. Donaldson and G. C. Miller, Coupled transport and photoreaction of napropamide in soils undergoing evaporation from a shalow water table, Environ. Sci. Technol., 1996, 30, 924-930.

13 J. P. Aguer, L. Cox, C. Richard, M. C. Hermosín and J. Cornejo, Sorption and photolysis studies in soil and sediment of the herbicide napropamide, J. Environ. Sci. Health, Part B, 2000, 35, 725-738.

14 C. Tomlin, The Pesticide Manual, Incorporating the Agrochemicals Handbook, 10th edn, British Crop Protection Council Publ., Surrey, U.K., 1994.

15 A. M. Botelho do Rego, L. F. Vieira Ferreira, Photonic and electronic spectroscopies for the characterization of organic surfaces and organic molecules adsorbed on surfaces, In: Handbook of Surfaces and Interfaces of Materials, Ed. H. S. Nalwa;, Academic Press, New York, 2001.

16 L. F. Vieira Ferreira, J. P. Da Silva, I. Ferreira Machado, T. J. F. Branco and J. C. Moreira, Surface photochemistry: dibenzo-p-dioxin adsorbed onto silicalite, cellulose and silica, J. Photochem. Photobiol., A, 2007, 186, 254-262.

17 J. P. Da Silva, L. F. Vieira Ferreira, A. M. Da Silva and A. S. Oliveira, Photochemistry of 4-chlorophenol on cellulose and silica, Environ. Sci. Technol., 2003, 37, 4798-4803.

18 J. P. Da Silva and L. F. Vieira Ferreira, Surface photochemistry of pesticides: An approach using diffuse reflectance and chromatography techniques, Environ. Sci. Technol., 2004, 38, 2849-2856.

19 J. A. M. Pulgarín and L. F. G. Bermejo, Determination of the pesticide napropamide in soil, pepper and tomato by micelle-stabilized roomtemperature phosphorescence, J. Agric. Food Chem., 2002, 50, 1002 1008 .

20 L. F. Vieira Ferreira, J. C. Netto-Ferreira, I. V. Khmelinskii, A. R. Garcia and S. M. B. Costa, Photochemistry on surfaces: matrix isolation mechanisms for study of interactions of benzophenone adsorbed on microcrystalline cellulose investigated by diffuse reflectance and luminescence techniques, Langmuir, 1995, 11, 231-236.

$21 \mathrm{~K}$. Hara and K. Baba, Photodissociation of $\alpha$-naphthol in solution: influence of hydrogen bonding, J. Chem. Soc., Faraday Trans. 2, 1975, 71, 1100-1108. 
22 H. Shizuka, H. Hagiwara and M. Fukushima, Laser flash photolysis study of the hydrogen atom transfer reaction from triplet 1-naphthol to ground benzophenone, J. Am. Chem. Soc., 1985, 107, 78167823.

23 M. Yamaji, T. Sekiguchi, M. Hoshino and H. Shizuka, Proton induced electron transfer reaction from triplet methoxynaphthalenes to benzophenone via triplet exciplex, J. Phys. Chem., 1992, 96, 93539359.

24 M. Lukeman, D. Veale, P. Wan, V. R. N. Munasinghe and J. E. T. Corrie, Photogeneration of 1,5-naphthoquinone methides via excitedstate (formal) intramolecular proton transfer and photodehydration of 1-naphthol derivatives in aqueous solution, Can. J. Chem., 2004, 82, $240-253$.

25 P. K. Das, M. V. Encinas, S. Steenken and J. C. Scaiano, Reaction of tert-butoxy radicals with phenols. Comparison with reactions of carbonyl triplets, J. Am. Chem. Soc., 1981, 103, 4162-4166.

26 T. Mori, M. Takamoto, H. Saito, T. Furo, T. Wada and Y. Inoue, Isolation of cyclohexadienone intermediates in the photo-Fries rearrangement of 2,4-dimethylnaphth-1-yl and 2,4-dimethylnaphth-2-yl 2,4,6-trimethylbenzoates, Chem. Lett., 2004, 33, 254-255.
27 W. D. Burgos, J. T. Novak and D. F. Berry, Reversible sorption and irreversible binding of $\alpha$-naphthol to soil: elucidation of processes, Environ. Sci. Technol., 1996, 30, 1205-1211.

28 M. C. Jiménez, M. A. Miranda, J. C. Scaiano and R. Tormos, Twophoton processes on the photo-Caisen and photo-Fries rearrangements. Direct observation of dienic ketenes generated by photolysis of transient cyclohexa-2,4-dienones, Chem. Commun., 1997, 1487-1488.

29 R. G. Weiss, V. Ramamurthy and G. S. Hammond, Photochemistry in Organized and Confining Media: A Model, Acc. Chem. Res., 1993, 26, $530-536$.

30 M. E. Sigman, J. T. Barbas, E. A. Chevis and R. Dabestani, Spectroscopy and photochemistry of 1-methoxynaphthalene on $\mathrm{SiO}_{2}$, New J. Chem., 1996, 20, 243-248.

31 B. Maillard, K. U. Ingold and J. C. Scaiano, Rate constants for the reactions of free radicals with oxygen in solution, J. Am. Chem. Soc., 1983, 105, 5095-5099.

32 O. Suchard, R. Kane, B. J. Roe, E. Zimmerman, C. Jung, P. A. Waske, J. Mattay and M. Oelgemöller, Photooxygenations of 1-naphthols: an environmentally friendly access to 1,4-naphthoquinones, Tetrahedron, 2006, 62, 1467-1473. 